\title{
A IMPORTÂNCIA DA FORMAÇÃO CONTINUADA NA PRÁTICA DOCENTE
}

\author{
Lucyelen Costa Amorim 1 \\ Mayara Cazadini Carlos ${ }^{2}$ \\ Adriana de Medeiros Marcolano Thebas ${ }^{3}$
}

Resumo: A formação continuada torna-se relevante quanto á capacitação do professor, pois os cursos auxiliam a adequar sua formação as necessidades do aluno e da escola. Por isso, é necessário que ele esteja em constante formação. O objetivo desse trabalho foi analisar como a formação continuada está presente no cotidiano escolar dos docentes e se tem auxiliado em seu processo pedagógico com seus alunos Foi aplicado um questionário de forma anônima a professores de Ciências, Química, Matemática e Português de escolas do município de Alegre ES. A maioria dos professores participa de cursos de formação continuada totalizando 93,3\%, dos trinta professores que responderam ao questionário 93,3\% disseram que os cursos auxiliam na hora de planejar as aulas e 100\% ou seja, todos os professores afirmaram que é necessário estar em constante formação. A formação continuada mostra-se como uma importante medida que possibilita ao professor suprir lacunas na sua formação inicial e se manter em constante aperfeiçoamento em sua atividade profissional.

Palavras-chave: Docente; Educação; Escola.

\footnotetext{
1 Ciências Biológicas/Instituto Federal do Espírito Santo - Campus Alegre, Brasil. E-mail: lucyelen_amorim@hotmail.com.br.

2 Ciências Biológicas/Instituto Federal do Espírito Santo - Campus Alegre, Brasil. E-mail: may_cazadini@hotmail.com.

${ }^{3}$ Letras/Faculdade de Filosofia Ciências e Letras de Alegre, Brasil. E-mail: marcolano20@hotmail.com.
} 